\title{
Consumo literario en lenguas indígenas: experiencias de revitalización desde el Sur de México**
}

\author{
Literary consumption in indigenous languages: \\ revitalization experiences from Southern Mexico
}

Consumo literário em línguas indígenas:
experiências de revitalização desde o Sul do México

\footnotetext{
* Doctora en Antropología por el Centro de Investigaciones y Estudios Superiores en Antropología Social (CIESAS-México). Profesora-investigadora de la Universidad Autónoma Benito Juárez de Oaxaca. Candidata a Investigador Nacional del Consejo Nacional de Ciencia y Tecnología (Conacyt). Colaboradora del Inali para el desarrollo de proyectos de revitalización lingüística en Oaxaca. Correo electrónico: lorenacordova64@gmail.com

** El artículo se basa en el trabajo de campo realizado en dos proyectos de investigación. El primero, Desarrollo de nidos lingüisticosy materiales para la revitalización de lengua y cultura chuj en el contexto escolar (agosto 2009-junio 2010), financiado por el Fondo para el Desarrollo de la Educación Intercultural Bilingüe, por medio de Innovación y Apoyo Educativo, AC, y con la colaboración del Ayuntamiento de Barcelona-Barcelona Solidaria y del Centro Unesco Cataluña. El segundo, Revitalización de lenguas en riesgo en el sur del país (octubre 2014-junio 2015), financiado por el Instituto Nacional de Lenguas Indígenas (Inali) y Zazanilli Cuentos A.C. Artículo de investigación recibido el 01/09/2015 y aceptado el o8/01/2016.
} 


\section{Cómo citar}

CóRdOVA HERnÁNDEZ, L. (2016). Consumo literario en lenguas indígenas: experiencias de revitalización desde el Sur de México. Revista CS, no. 18, pp. 37-61. Cali, Colombia:

Facultad de Derecho y Ciencias Sociales, Universidad Icesi.

DOI: http://dx.doi.org/10.18046/recs.i18.2053 


\section{Resumen}

Abstract

Resumo

A partir de distintas experiencias etnográficas del Sur de México, este artículo analiza la manera en que los programas o proyectos de literacidad en lenguas indígenas para la revitalización lingüística son concebidos por los agentes revitalizadores. Desde el campo de la revitalización, el fomento a la literacidad es un paso previo a la producción y consumo de literatura en dichas lenguas. Específicamente este artículo discute la producción de bienes literarios a partir de la competencia lectora de los consumidores potenciales. Así se interroga cómo la literacidad es imaginada como un proceso de alfabetización que, al final, no desemboca en la formación de lectores.

\section{PALABRAS CLAVE:}

Revitalización lingüística | literacidad | consumo literario | literatura en lenguas indígenas

This article analyzes, from several ethnographic experiences in Southern Mexico, the way in which agents for language revitalization design the programs or projects of literacy in indigenous languages. From the field of revitalization, promotion of literacy is a prerequisite for the production and consumption of literature in these languages. Mainly, this article discusses the production of literary goods from the reading skills of potential consumers. In addition, it interrogates how literacy is imagined as an education process that at the end does not result in the training of readers.

\section{KEYWORDS:}

Language revitalization | literacy | literary consumption | literature in indigenous languages

A partir de diferentes experiências etnográficas do Sul do México, este artigo analisa a maneira em que os programas ou projetos de alfabetizações em línguas indígenas para a revitalização linguística são concebidos pelos agentes revitalizadores. Desde o campo da revitalização, o fomento à alfabetização é um passo prévio à produção e consumo de lite- 
ratura nestas línguas. Especificamente este artigo discute a produção de bens literários a partir da competência de leitura dos consumidores potenciais. Assim se interroga como a alfabetização é imaginada como um processo de alfabetização que, ao final, não desemboca na formação de leitores.

\section{PALAVRAS CHAVES:}

Revitalização linguística | alfabetização | consumo literário | literatura em línguas indígenas 


\section{Introducción}

En Latinoamérica, durante más de cinco siglos, las lenguas indígenas han sufrido distintos procesos de desplazamiento sociolingüístico frente al español y/o portugués. En este proceso, su estigma es no poseer "estatus de lenguas", pues la mayoría de ellas son solo de tradición oral. La población, indígena y no indígena, considera que estas lenguas no poseen gramática y mucho menos una tradición escritural y literaria que les dé un estatus mayor. En México, el proceso de desplazamiento lingüístico se incrementó de manera abrupta en la primera mitad del siglo XX. En este proceso la escuela se convirtió en el espacio idóneo para desplazar a las lenguas indígenas, bajo la pretensión de construir un Estado posrevolucionario y una nación "moderna" (Mijangos y López, 2011).

El desplazamiento de lenguas indígenas ha preocupado a investigadores, activistas, lingüistas nativos y no nativos, así como a miembros de distintos movimientos indígenas. En las últimas dos décadas, dicha preocupación ha derivado un sinfín de acciones a favor de las lenguas diseñadas tanto para la investigación, desde la lingüística descriptiva y la documentación lingüística, como para la promoción pública de ellas (diseño de materiales educativos, juegos, paisaje lingüístico, traducciones legales y literarias, entre otras acciones). Sin embargo, la producción de estos bienes y su consumo son reducidos, pues si bien son herramientas simbólicas -que instituciones estatales y movimientos indígenas promueven-, no se convierten en materiales culturales que se inserten en la vida cotidiana de los hablantes; y se convierten en una suerte de curiosidad o souvenir sin circulación ni intercambio amplio.

Este artículo analiza, a partir de distintas experiencias etnográficas del Sur de México, la manera en que son concebidos los programas o proyectos de literacidad en lenguas indígenas para la Revitalización Lingüística (RL). Desde el campo de la revitalización, el fomento a la literacidad es un paso previo a la producción y consumo de literatura en estas lenguas. En específico, se problematiza la producción de bienes literarios a partir de la competencia lectora de los consumidores potenciales. Asimismo, cómo la literacidad es imaginada en un proceso de alfabetización que, al final, no desemboca en la formación de lectores.

El artículo se encuentra divido en cinco apartados. En el primero se hace referencia al campo y proceso de la RL; es decir, la manera "ideal” en que se imagina la revitalización, haciendo referencia a cómo la planificación y política lingüística que se desarrolla en México se traslapa con la educación dirigida a la población indígena y a la alfabetización. De esta manera, la RL no es practicada como un campo abierto para la recuperación de un uso amplio de las lenguas que se están desplazando sino como un ingrediente secundario de otros procesos e intereses. En segundo lugar, se hace referencia a cómo la literacidad se convierte en una de las herramientas principales de la revitalización (Moore y Macdo- 
nald, 2013). Sin embargo, en la práctica, esta literacidad es reducida al conocimiento de un alfabeto y la gramática de la lengua, dejando de lado la "competencia pragmática" de los aprendices. En el tercer apartado se exponen algunas experiencias etnográficas, en torno a proyectos de RL desarrollados en el Sur de México, en los estados de Chiapas y Oaxaca, en los que se ha dado lugar especial a las clases de lengua y a la producción de material escrito (cuentos, monografías, etc.). Rige este apartado la pregunta sobre cómo se fomenta el consumo de estos materiales dentro de las comunidades de hablantes y de no hablantes de lenguas indígenas. El penúltimo apartado hace una problematización en torno al consumo literario de lenguas indígenas y cómo se promueve la formación de nuevos lectores. Por conclusión, más que cerrar o brindar soluciones, este artículo inicia una discusión en torno al consumo literario en lenguas indígenas y por qué, en el Sur de México, se está aún lejos de tener evidencias sobre públicos amplios de literatura en lenguas indígenas y, por ende, en la RL de las mismas.

\section{El proceso de la revitalización lingüística}

La RL, entendida como el "desarrollo de programas que se traducen en el restablecimiento de una lengua que ha dejado de ser la lengua de comunicación en la comunidad de habla y el restablecimiento de su utilización plena en todos los ámbitos de la vida" (Hinton, 2001:5), es un proceso de larga duración en el que una acción o una metodología no puede garantizar la revitalización de la lengua de interés.

Es un proceso multidimensional y multitécnico en el que el contexto social determina la manera de generar acciones a favor de la lengua a revitalizar. Desde hace varias décadas se conocen procesos de revitalización emprendidos en diferentes lugares y que han logrado comenzar a revertir el desplazamiento lingüístico: como la experiencia maorí en Nueva Zelanda, cuyos esfuerzos de revitalización son considerados como una oposición al colonialismo (Skerrett, 2012); como el caso vasco cuyo procesos de revitalización han tratado de incidir en la diáspora vasca en distintos lugares del mundo, concibiendo el proceso revitalizador como acto político y, por ende, identitario (Valadez, Etxeberria y Intxausti, 2015). Aunque estas experiencias han comenzado a revitalizar las lenguas, sus metodologías no pueden ser replicadas a cualquier otro caso. Los procesos de reversión del desplazamiento obedecen a contextos políticos, educativos, económicos, etc., particulares y distintos.

El éxito de los procesos de RL depende del modo particular o local en que los grupos sociales se organizan para reestablecer el cotidiano proceso comunicativo en la lengua amenazada. Las metodologías y los soportes escritos, digitales, artísticos, 
y otros, son formas de promoción de la lengua y estímulos simbólicos para su restablecimiento; pero no aseguran su revitalización. ${ }^{1}$

Si bien el proceso de RL depende de la organización social, los actores necesitan certezas yestímulos educativos, económicos, políticos, artísticos, etc., que permitan influir de manera positiva en dicha organización. El papel de científicos, activistas, promotores culturales, educadores, etc. es fundamental para crear una plataforma que permita que los actores sociales comiencen a tener una nueva percepción sobre ser hablantes de lenguas indígenas, debido a que pueden ayudar a generar diversas maneras de planificación lingüística o promover "decisiones en torno a qué idiomas son reconocidos y utilizados en un país" (Alimi, 2015: 2), e inciden directamente en su planificación y política educativa.

Es necesario recalcar que los planificadores del lenguaje son los "árbitros de la política lingüística" (Language Policy Arbiters) y "tienen una cantidad desproporcionada de impacto en la política lingüística y programas educativos" (Johnson y Johnson, 2015: 222); pero no son los revitalizadores de las lenguas. Los agentes revitalizadores son aquellos miembros de los grupos sociales que transmitirán, aprenderán y utilizarán las lenguas de interés. Sin embargo, al poner en marcha políticas y planificación lingüística, el reconocimiento a dichos agentes es casi nulo.

Los procesos de revitalización son parte de las políticas lingüísticas de un grupo, comunidad, estado, etc., y se planifican desde dos ámbitos interdependientes: "desde abajo" (bottom-up approach) (Córdova, 2009; Kingsley, 2009) y "desde arriba" (topdown approach) (López, 2008). Actualmente, en el caso mexicano, las sugerencias de planificación lingüística y revitalización "desde arriba" se emiten en el Instituto Nacional de Lenguas Indígenas (Inali) o desde la Secretaría de Educación Pública (SEP); un nivel intermedio de planificación son los institutos o centros de lenguas indígenas². Las instituciones delimitan acciones "formales" a favor de las lenguas a partir del mar-

1. Con estímulos simbólicos me refiero a ejercicios como, por ejemplo, el "activismo digital de lenguas" creado recientemente por la Red de Activistas Digitales en América Latina: de acuerdo a su sitio en Internet, el objetivo de esta red es "reunir a varios activistas digitales quienes son impulsores para sus lenguas en línea para que puedan intercambiar experiencias y enseñar/aprender nuevas técnicas y estrategias para crear una nueva generación quienes revitalizan sus lenguas a través de medios digitales". Si bien el trabajo de la Red es loable, esto no quiere decir que el proceso emprendido o las personas participantes estén revitalizando lenguas en términos de uso y transmisión intergeneracional. El "activismo digital” es un medio que "ofrece herramientas, espacios, canales y experimentos en los que recobrar la subjetividad política a través de la creación e inteligencia colectiva y la redefinición constante de los códigos y prácticas discursivas, comunicativas y tecnológicas que definen nuestra realidad social (Barandiaran, 2003: 1). En este sentido, el activismo digital de lenguas indígenas es un contrapoder a la representación lingüística y discursiva en América Latina, y están generando acciones que extendidas y socializadas con las comunidades y grupos sociales, pueden ser herramientas o insumos de la RL.

2. Centro de Desarrollo y Estudio de las Lenguas Indígenas (Cedelio) en el estado de Oaxaca. Centro Estatal de Lenguas, Arte y Literatura Indígenas (Celali), en Chiapas. El ejercicio de planificación de algunas lenguas mayas que se hablan en la frontera del estado de Chiapas con Guatemala, se hace a partir de las acciones realizadas por la Academia de Lenguas Mayas de Guatemala. 
co legal establecido3. Entre la amplia diversidad lingüística de México, las estrategias "desde arriba" derivan en el reconocimiento y aplicación de investigaciones desde una perspectiva general hacia todas las lenguas y variedades lingüísticas.

Por ejemplo, en el Inali hay un proyecto de investigación para el desarrollo de "gramáticas pedagógicas" con las que se pretende fomentar el "uso" de las reglas gramaticales de una lengua a partir de su presentación, explicación y práctica ${ }^{4}$. Sin embargo, esta elaboración no tiene como resultado inmediato la incorporación de esta gramática a las estrategias de enseñanza de los profesores que atienden a la población que habla la lengua de la que ha derivado la gramática, por lo que dicha acción tardará largo tiempo en ser instrumento de enseñanza en las comunidades de habla, y más en tener algún efecto revitalizador.

Por su parte, la perspectiva "desde abajo" es considerada más viable para iniciar procesos revitalizadores, pues aquellas iniciativas surgen de la organización sociopolítica de los actores y/o agentes revitalizadores con el colectivo o comunidad.

El involucramiento e iniciativa de las propias comunidades que han incrementado el ímpetu y la sustancia para los esfuerzos de planeación [no es] donde las organizaciones gubernamentales no indígenas y no gubernamentales han jugado un papel significativo [...]. Es justo decir que los esfuerzos que han tenido grandes impactos y duración son aquellos iniciados y continuados por las comunidades indígenas (Hornberger, 1996: 357).

El desarrollo de micropolíticas revitalizadoras permite impulsar estrategias más inmediatas que las políticas generadas desde arriba. Sin embargo, es necesario apuntar que aunque estas estrategias son más directas y esperanzadoras, no necesariamente desembocan en la reversión del desplazamiento lingüístico.

Por ejemplo, desde hace más de tres años en la comunidad de origen chocholteco (ngigua/ngiba) Suchixtlahuaca (Oaxaca), se comenzaron a impartir clases de lengua chocholteca a nivel de educación primaria. La iniciativa surgió del posicionamiento

3. Inali responde a la Ley de Derechos Lingüisticos de los Pueblos Indígenas (2003) y sus acciones se fundamentan en documentos internacionales como Pacto Internacional de Derechos Civiles y Politicos (1966), Convención sobre la Proteccióny Promoción de la Diversidad de las Expresiones Culturales (1972), Declaración de la UNESCO sobre Diversidad Cultural (2001), entre otras.

4. Estas gramáticas pedagógicas se inspiran en la propuesta de Luiz Amaral de la Universidad de Massachusetts Amherst, quien ha trabajado con lenguas indígenas de Brasil, y cuyo objetivo de 2013 a 2016 es presentar la gramática pedagógica de la lengua wapichana, así como de otras cuatro lenguas ikpeng, karajá, kawaiweté y paresi. "Lo que esperamos es que estas gramáticas se utilicen en proyectos de educación de lenguas indígenas. Queremos que las gramáticas sirvan para apoyar la enseñanza de lenguas indígenas en las comunidades. Otro objetivo es ayudar a la formación de maestros. Muchas veces los maestros de lengua indígena no tienen una formación específica en su lengua, entonces van a enseñar las lenguas porque las hablan, conocen el vocabulario, pero no conocen las estructuras de sus lenguas" (Primer Taller de Gramáticas Pedagógicas de Lenguas Otomangues, Ciudad de Oaxaca, Inali y Biblioteca Juan de Córdova de la Fundación Alfredo Harp Helú. 22 de julio a 10 de agosto de 2015). 
político de las autoridades municipales y de un acuerdo general con padres de familia y profesores. Como Suchixtlahuaca ya no contaba con hablantes de la lengua, la autoridad municipal asumió los gastos del traslado de personas reconocidas como "profesores de la lengua" de un poblado vecino, así como su respectivo sueldo. Con el paso del tiempo, las siguientes autoridades manifestaron que las clases de lengua chocholteca eran un gasto fuerte para el municipio, por lo que se necesitaba ayuda gubernamental para sostenerlas. En una reunión con autoridades y promotores chocholtecos y personal del Inali, la Secretaría de Asuntos indígenas de Oaxaca (SAI) y el CEDELIO, el presidente municipal de Suchixtlahuaca manifestó:

[...] las clases de lengua se han cancelado porque los padres de familia no se ponen de acuerdo si quieren que sigan. Además, quieren que se realicen los sábados porque en días de clase [entre semana] se pierde tiempo para aprender los temas de la escuela. Por eso es necesario esperar a que [los padres de familia] se pongan de acuerdo, para saber si van a seguir con las clases o no y si sí programar actividades (Tlacotepec Plumas, 11/09/2015).

La nota de campo muestra varios elementos de los cuales se pueden inferir, junto con el contexto previo, cuatro aspectos: 1 ) las clases de lengua no fueron bien consensuadas con los padres de familia desde el comienzo; 2) los padres de familia perciben el proceso de enseñanza de la lengua como un obstáculo para llevar a buen término el proceso de educación formal; 3) el discurso público del presidente es de "neutralidad" y "respeto" a las decisiones del colectivo, para no emitir su postura en torno a que la inversión económica y humana para las clases de lengua no corresponde al municipio; y 4) el proceso de RL tuvo un planteamiento inicial muy débil, al considerar los sueldos y viáticos de los profesores: si un proyecto de RL depende de un presupuesto, el proceso revitalizador terminará junto con el financiamiento. ${ }^{5}$

Aunque este proceso a favor de la lengua chocholteca fue iniciativa local y su éxito fue casi nulo, hacer referencia a la participación de los actores sociales en los procesos de revitalización se ha vuelto una suerte de panacea. Se podría decir que los hacedores de políticas y planificación lingüística, desde el ámbito oficial o desde arriba, se han "sensibilizado" sobre la participación directa de los actores en el proceso de revitalización. Pero es solo un discurso que se justifica con los aportes de distintos sectores a favor de la RL, pero en los procesos didácticos, metodológicos, políticos, entre otros, está lejos de la realidad.

Entre de las ideologías en torno a la RL, además de considerar la participación de los actores locales como "fórmula exitosa", se considera también casi como regla metodo-

5. El término de un proyecto de RL como resultado del recorte o fin del financiamiento no es propio de los países latinoamericanos. También sucede en países como Estados Unidos (Haynes, 2011), por lo que es necesario insistir en que en la RL no es el tema del incentivo económico lo que permite su éxito. 
lógica la enseñanza de lenguas. Hasta hoy la mayoría de propuestas de RL promueven como perspectiva revitalizadora la enseñanza de lenguas y, con ello, su escritura.

Como se mencionó líneas arriba, la planificación y, en este caso, la RL han ganado mucho terreno en el ámbito de la educación formal: se ha llegado a confundir o a traslapar con la Educación Intercultural Bilingüe EIB. Con ello, se ha dejado de reconocer que la EIB es un espacio importante para la RL pero no el único para reestablecer el uso de las lenguas indígenas. La EIB es parte de la materialización de los derechos educativos y culturales de los pueblos indígenas, pero no el único espacio en el que se generan interacciones comunicativas. Dentro de este traslape, incluso malentendido, no sólo existen casos en México sino también en Centroamérica. Por ejemplo, el proyecto de revitalización de la lengua nahuat/pipil en El Salvador (Lemus, 2010), una lengua considerada "moribunda" en el contexto salvadoreño y cuya propuesta de revitalización contrasta con varias teorías de enseñanza de lengua, sin ser propiamente exitosa, abriendo un campo de discusión importante (Durán, 2013).

La RL, desde una perspectiva más procesual y comunitaria, aboga por el incremento de una "competencia comunicativa pragmática" dentro de los potenciales hablantes: por ésta se reconoce que los hablantes o actores sociales (re)crean su percepción de la realidad social.

La competencia es una capacidad para gestionar el complejo de los recursos comunicativos que los individuos poseen y despliegan, dichos recursos socialmente se generan, distribuyen y organizan a través de prácticas de socialización comunicativas y de lenguaje interpersonales en la comunidad. [Por lo tanto] el despliegue de estos recursos comunicativos contribuye a crear las categorías y estructuras sociales (Makihara, 2013: 440).

El traslape entre la RL y la EIB es una forma de reducir la (re)creación de las categorías sociales desde los códigos determinados en la lengua. En México, la práctica de la EIB es sólo una traducción de los modelos monolingües y etnocéntricos que han desplazado a las lenguas indígenas. Aunque existen procesos dentro de la educación formal que practiquen y aboguen por la incorporación de las epistemologías nativas y el uso pleno de las lenguas indígenas. ${ }^{6}$

La incursión de las lenguas indígenas en comunidades con alto grado de desplazamiento se ha realizado por medio de "clases de lengua", pues se tiene la idea de que

6. Hasta hace pocos meses en el estado de Oaxaca los profesores de educación básica de la Sección XXII de la Coordinadora Nacional de Trabajadores de la Educación CNTE, abogaban por la incorporación de la enseñanza de saberes comunitarios dentro del plan de educación indígena y no indígena, no sólo con fines educativos sino como forma de resistencia política frente a las reformas educativas propuestas por el gobierno federal. Incluso, se realizaban encuentros intercomunitarios en los cuales se hacían concursos e intercambios de conocimientos con pertinencia cultural llamados "Guelaguetza pedagógica”. Sin embargo, este proceso permanece incipiente y se ha visto obstaculizado por procesos administrativos y laborales de los profesores. 
las lenguas indígenas se deben enseñar de manera similar al alfabeto o la gramática del español. Enseñar estas lenguas y aprender a escribirlas es un proceso complejo, en el cual la RL y el uso de la lengua escrita más allá de lista de palabras y como recurso literario se obnubila.

\section{Literacidad para la revitalización de lenguas}

En el campo de estudio de la RL, hoy se hace referencia a los procesos de "literacidad en lenguas indígenas" (indigenous literacy), entendiendo literacidad como "la organización social de la lectura y escritura para dar cuenta de sus múltiples usos en los contextos locales, [en ella se] destaca que la pluralidad de lo letrado es concebida como histórica y culturalmente construida y, por ende, inserta en relaciones de poder" (Cragnolino y Lorenzatti, 2013: 200).

La literacidad es una forma de concebir la lectura y escritura desde una perspectiva amplia, que no se restringe a las funciones comunicativas escolares sino a todo los ámbitos de la vida social. Intentar poner en marcha procesos de literacidad en lenguas indígenas, en contextos generalmente bilingües y multilingües, es indispensable en términos de restablecimiento del uso de las lenguas en todos los espacios posibles, en especial el de la familia. "La familia y los hogares se constituyen en espacios específicos donde se desarrollan prácticas letradas y éstas se relacionan con otros espacios comunitarios y, en particular, los escolares" (Cragnolino y Lorenzatti, 2013: 200).

Los estudios científicos de la literacidad han promovido la idea de que en la infancia la adquisición de los procesos de lectura y escritura son más eficaces y positivos, no sólo en términos comunicativos sino también cognitivos, afectivos y con efectos en el cambio social.

La alfabetización en la infancia temprana es uno de los mecanismos propuestos [en casos donde la] pobreza actúa como una profunda determinante social de los resultados de salud infantil, no sólo para el desarrollo de la salud física, sino también a la de la salud cognitiva, conductual y emocional (Navsaria y Sanders, 2015: 1274).

Los procesos de literacidad y, en su caso, los procesos de alfabetización en lenguas indígenas muestran un menor indicio de eficacia. No solo a causa de sus escasos insumos humanos y materiales, también porque el derecho a la alfabetización y por ende el disfrute de una literacidad ampliada es violado. Respecto al derecho a la alfabetización en América Latina, Emilia Ferreiro menciona:

[...] el foco de atención lo constituyen aquellos niños que, aunque puedan acceder a la escuela pública, permanecen poco tiempo en ella, no solamente por la necesidad de incorporarse a actividades productivas sino también porque, de una u otra manera, han sido mal incorporados y 
terminan siendo expulsados por un sistema educativo que no sabe cómo alfabetizarlos. [Interesa saber] cómo puede alfabetizarsemejor a quienes, luego de pasaralgúntiempoenlaescuelapública, terminarán engrosando las filas de los analfabetos del futuro (Ferreiro, 2012:9).

El derecho a la alfabetización no se cumple en la mayoría de los sectores sociales cuya vulnerabilidad no permite una planificación y aplicación funcional para que estos sujetos no sean los analfabetos del futuro. Esta violación permanece latente en sectores hablantes del español, pero se incrementa en términos de las lenguas indígenas. En el caso mexicano, aunque existen programas de estudios avanzados que proponen profundizar conocimientos pedagógicos y gramaticales para la enseñanza de lenguas ${ }^{7}$, el proceso alfabetizador en dichas lenguas y la adquisición de una competencia pragmática de la lecto-escritura no se ha traducido en las prácticas de los docentes de educación básica $y$, mucho menos, en el ámbito familiar.

La violación de la alfabetización se ha dado generacionalmente: probablemente los profesores que ahora alfabetizan fueron violentados en su proceso alfabetizador provocando con ello que sus alumnos cuenten con la misma suerte. Los padres de familia de estos niños son, en la mayoría de casos, personas mal alfabetizadas. Si sumamos barreras culturales e idiomáticas interpuestas a partir de la estigmatización de las lenguas indígenas, se obtiene nula literacidad en estas lenguas. Sin embargo, el estatus de la lengua escrita adquiere omnipresencia por una fuerte inclinación a tener el mejor alfabeto de una lengua indígena. Poseer textos escritos se convierte en un símbolo importante de la lengua, aunque existan pocas personas alfabetizadas para lograr la decodificación de los mismos.

En todas las sociedades alfabetizadas se otorga poder supremo al texto escrito; los hablantes de lenguas indígenas de tradición oral no son la excepción. En muchas experiencias, cuando se llega a una comunidad o población con mayoría indígena y se busca a los hablantes de las lenguas para conseguir algún tipo de información, los pobladores envían a los investigadores con el "conocedor de la lengua". Es decir, aquel que por su edad y estatus social es reconocido como el mejor hablante y/o aquel que ha sido reconocido por las instituciones como el escritor y traductor oficial de dichas lenguas. El primer caso comienza a ser menos recurrente, pues la mayoría de estos hablantes, debido a su avanzada edad, han ido falleciendo, siendo el segundo caso el más repetido y actual.

El escritor y traductor también es el que se dedica a alfabetizar y/o enseñar la lengua en la escuela; por lo general, muchos profesores de la educación pública en los contextos indígenas son jóvenes que ya no hablan una lengua o que son hablantes de una lengua

7. Algunos programas académicos en México: Posgrado en Lingüística Aplicada del Centro de Estudios de Lenguas Extranjeras de la Universidad Nacional Autónoma de México; Posgrado de Lingüística Indoamericana del Centro de Investigaciones y Estudios Superiores en Antropología Social; Diplomado de Enseñanza de Lenguas Indígenas del Inali. 
distinta a la del lugar. Este alfabetizador, por lo general, fue alfabetizado en español y de la manera menos funcional que se puede imaginar.

Los esquemas y estructuras de enseñanza de la lengua indígena son adaptados desde los modelos de enseñanza del español. Debido a su papel de alfabetizador de la lengua indígena, el interés es solo por el alfabeto y el intento, casi siempre mal logrado, de escribir frases y no discursos. Por tal motivo, el alfabetizador se convierte en un seguidor acérrimo del alfabeto y la traducción de textos, pero no un transmisor del discurso oral en lengua indígena, lo que en términos de revitalización es considerado una fosilización de la lengua (Flores y Córdova, 2012). Asimismo, este alfabetizador no necesariamente es escritor o lector.

La continuidad y/o discontinuidad de la oralidad y escritura es un tema que se debate tanto en el ámbito de las lenguas indígenas como en el de las llamadas lenguas modernas. Desde hace más de una década, con una perspectiva crítica y holística, se ha comenzado a defender la continuidad y complementariedad del binomio oral/escrito a partir de lo que se entiende por literacidad. Sin embargo, "la función del narrador escritural ha suplantado al narrador oral” (Padrón, 2000:12). El discurso escrito otorga veracidad y, con ello, estatus a lectores y escritores. Los hablantes de lenguas indígenas no son ajenos a este tipo de procesos y aunque se reconoce que históricamente el recurso escrito en términos alfabéticos es un proceso de corte occidental y colonial, los promotores de las lenguas indígenas e incluso los propios investigadores fomentan dicho proceso, haciendo de la escuela el único lugar para adquirirlo.

Los autores que hablan de "mentes alfabetizadas" lo hacen con el propósito de alertarnos. Se refieren con este término a esta estructura mental en la que sujeto y hablante son desplazados por el lector. [Estas mentes] son producto de la huella dejada por una "cultura" que pregona al alfabetismo como una condición universal de las sociedades humanas que desestima sociedades orales y olvida que - aún en las sociedades con escritura- el discurso es irremplazable. Igualmente parece olvidar que lo escrito adquiere existencia social, pública sólo si éste es convertido en objeto de discurso. [Existe una] visión mesiánica de la institución escolar y de la alfabetización. Ambas nos han sido vendidas como recursos para la mágica transformación individual y social: de mente analfabeta a mente alfabetizada, y de sociedad subdesarrollada a sociedad que transpira modernidad (Padrón, 2000: 12-13).

A partir de lo anterior, se puede observar que si bien la alfabetización puede ayudar a generar cambios sociales de manera positiva, este tipo de cambio no tiene lugar de manera espontánea. Es decir, no basta solo con incorporar el recurso escrito de una lengua para que sus hablantes cambien de estatus o tengan una literacidad en la lengua de interés. 
Cabe señalar que el proceso en el que se enmarca la presente discusión enfatiza en el tipo de consumo y producción escrita dirigido a población poco escolarizada y poco alfabetizada, y a quienes pueden ser agentes de revitalización comunitaria. Asimismo, a quienes se les han mostrado procesos de institucionalización de la lengua, ya sea por la escuela o por los propios lingüistas, como alternativas para la RL. Esto quiere decir que no se deja de reconocer el impacto positivo hacia la literacidad en lenguas indígenas que tienen los usos contemporáneos de escritura de lenguas indígenas en ámbitos no institucionales. Por ejemplo, la creación de paisaje lingüístico por medio de colectivos de "acción poética" en lenguas indígenas de Perú (Yataco y Córdova). Asimismo, procesos de uso en Facebook del maya yucateco en México para la generación de redes sociales de activismo a favor de las lenguas (Cru, 2015). Sin embargo, dichos procesos son parte de una excepción y no de una regla en la población hablante o usuaria de una lengua indígena escrita.

En términos de RL se observa con mucho interés la manera en que dicha literacidad está siendo enunciada y practicada, pues si bien se entiende como competencia pragmática y no sólo gramatical y alfabética sobre una lengua, se practica como sinónimo de alfabetizar desde una perspectiva "reduccionista" y no para utilizar los recursos escritos y orales existentes. En contextos monolingües, por ejemplo, donde sólo se habla español, el proceso de literacidad es un poco más sencillo de imaginar. Sin embargo, en contextos bilingües y multilingües, como en los que se desenvuelven los hablantes de lenguas indígenas en México, este proceso es más complejo, aunque de ser aplicado de manera amplia y funcional podría dar muchas herramientas cognitivas y sociales a los hablantes de la lenguas indígenas.

El lenguaje oral de los niños y el desarrollo de la alfabetización temprana sirven de base para las habilidades de lectura y posterior éxito académico en general. Está bien documentado que los niños con habilidades lingüísticas orales bajas están en riesgo de malos resultados a medida que progresan a través de la escuela. [...] Por desgracia, se ha prestado insuficiente atención a la lengua y la alfabetización de los niños que aprenden dos idiomas o aprenden [en la escuela] en dos idiomas. [En este contexto] el idioma del hogar y las habilidades de alfabetización también son relevantes para los resultados a largo plazo de los aprendices de dos lenguas. En las familias de inmigrantes, las habilidades de los niños para hablar la lengua del hogar de sus familias están relacionadas con la calidad de las relaciones dentro de la familia y de las medidas de ajuste psicosocial (Hammer, Hoff, Uchikoshi, Gillanders, Castroe y Sandilos, 2014: 716).

La literacidad en lenguas indígenas permitirá que en contextos bilingües los niños y aprendices adquieran mayores habilidades en torno a la lengua oral y escrita, así como un desarrollo y disfrute de sus derechos. Sobre todo si se fortalece en el ámbito familiar y en otros ámbitos comunicativos. Sin embargo, en términos de RL se observa 
que la familia ha dejado de ser el transmisor principal en la adquisición temprana de la lengua indígena; y cuando ingresa a la escuela el niño tiene pocas habilidades tanto en lengua indígena como en español.

Si a esto se suma que el patrón de enseñanza y las habilidades adquiridas no serán propicios para un desenvolvimiento cognitivo y social pleno, los procesos de literacidad y RL poco prometen al futuro de las lenguas indígenas y a la formación de lectores. Aunque esto poco se perciba entre investigadores, profesores, alfabetizadores y promotores culturales.

A continuación, se muestran apuntes etnográficos de dos estados del sur de México: Chiapas y Oaxaca, ambos de amplia diversidad lingüística y donde hasta ahora no se puede hablar de lenguas revitalizadas ni de producción y consumo literario amplio en lenguas indígenas.

\section{Los procesos de literacidad en el sur de México}

Como se comentó en párrafos anteriores, el bajo estatus de las lenguas indígenas se justifica, en gran medida, por no poseer escritura y/o soportes escritos amplios. Sin embargo, cuando se colabora de manera directa con diferentes comunidades de hablantes se puede atestiguar que no solo es la "ausencia" de escritura lo que motiva este estatus, sino que los avances en términos de literacidad son reducidos y solo se utilizan retóricamente a favor de las lenguas.

Una de las mayores problemáticas a las que se enfrenta la divulgación de los textos escritos en lenguas indígenas es la diversidad dialectal, difícil de cuantificar, y también un instrumento de poder político para los propios alfabetizadores y/o promotores. Dentro de la experiencia mexicana, y en especial en el Sur del país, los esfuerzos de estandarización de las grafías de una lengua con poca tradición escrita han sido priorizados tanto en términos de fortalecer el uso de la lengua como de generar material escrito.

Por ejemplo, en el último trimestre de 2014 se comenzó a tener acercamiento con un Asesor Técnico Lingüístico ATL del Nivel de Educación Indígena hablante de la lengua chontal de Oaxaca ${ }^{8}$. La idea era comenzar un proyecto de revitalización cercano a los profesores de educación indígena en el área chontal que les sirviera para ser agentes revitalizadores de dicha lengua. En la primera reunión formal con el ATL se le explicaron las intenciones de generar un proyecto revitalizador chontal; él manifestó: "[...] lo que necesitamos en la zona chontal alta es un alfabeto práctico 
que nos ayude a escribir y enseñar la lengua. Eso nos ayudaría mucho" (Notas de campo, 4 de febrero de 2015).

A partir de lo expresado por el ATL, se trató de puntualizar algunos aspectos en torno a la RL y al interés por el fomento a la oralidad. Asimismo, tratar de orientar las necesidades a aspectos prácticos que permitieran a los profesores enseñar la lengua chontal. Se acordó que personal del Inali generaría un taller de enseñanza de la lengua indígena como segunda lengua desde el enfoque comunicativo. Con ello se podrían beneficiar más comunidades. El ATL aceptó la propuesta y concluyó "sí, está muy bien la idea del taller y ya después [en otro taller] la escritura con un alfabeto práctico" (Notas de campo, 4 de febrero de 2015).

$\mathrm{El}$ alfabeto práctico se refiere a la estandarización de la escritura de las variedades dialectales y a la creación de normativas en torno a las grafías a utilizar para el alfabeto. La estandarización tiene más relación "con cómo ocurre el reconocimiento social de un estándar y qué factores sociales, políticos e históricos hacen posible este proceso" (Avilés y Rojas, 2014:146), que con un entendimiento o inclusión de la diversidad dialectal. Los procesos de estandarización lingüística forman parte, en el nivel simbólico, de los procesos de conformación de las naciones modernas, específicamente, de su 'invención metadiscursiva' (Avilés y Rojas). En este sentido, y contradictoriamente, los grandes debates que existen dentro de las Academias de Lenguas, por ejemplo, de la lengua mixteca en Oaxaca o de las lenguas mayas en Chiapas, es sobre la invención de un alfabeto que pueda mantener un estatus parecido al español, sin importar el ejercicio de poder vertical que la estandarización puede implicar.

Contradictoriamente, los defensores de la diversidad lingüística indígena pueden generar las mismas acciones homogeneizadoras de los promotores del monolingüismo español. La estandarización de las grafías es un ejercicio de poder que se justifica para la obtención de un alfabeto y escritura "correcto": y se reiteran las estructuras colonizadoras y euro centristas que muchos de los defensores de las lenguas indígenas denuncian.

Por ejemplo, en el caso de la lengua chuj la estandarización de las grafías es una disputa de poder religioso más que un proceso lingüístico. Quienes son de filiación católica respetan las grafías desarrolladas por la Academia de Lenguas, mientras los de filiación protestante respetan y "entienden" las grafías y textos religiosos producidos y/o traducidos por su grupo. Esta lucha religiosa pasiva no sólo se observa en el plano escritural sino también en el oral, donde se pensaría que dicho proceso no se da, sobre todo cuando se piensa en fortalecer el uso de la lengua. Un catequista católico hace referencia a la revalorización de la lengua chuj por medio de la formación de un coro de jóvenes para "cumplir, "por medio de los cantos, las intenciones de Jeremías" (Comunicación personal, 23 de noviembre de 2008). 
El ideal del proyecto es "tener un coro chuj”, pero durante la época más ortodoxa del catolicismo, así como en la liberacionista y en la actual, nunca se promovió, al menos en esta región chuj, el uso de la lengua indígena en los cantos. Esto plantea un problema para el catequista, pues aunque se tiene la intención de llevar el proyecto, "no hay canciones católicas en chuj y ahora se tiene que conseguir quién las haga”. Este hecho hace notar que pasará mucho tiempo antes de que este proyecto se pueda llevar a cabo, pero lo que resulta interesante no es que se tenga las intenciones de crearlo, sino el incentivo ideológico que está motivando la creación de dicho coro (Córdova, 2009: 113).

Este ejemplo evidencia claramente que al hablar de estandarización no sólo se está hablando de estandarizar grafías sino de la ideología de normativizar muchas de las actividades en torno a la lengua. La lengua se norma en cada una de las actividades no sólo de acuerdo a cómo se escribe sino también a cómo y quién la utiliza, lo que en términos de RL es poco esperanzador. Este proceso de estandarización y sus pocos frutos en la RL y la literacidad en las lenguas indígenas no sólo se evidencia en la lengua chuj del estado de Chiapas, sino también en lenguas como el chocholteco o el ixcateco en el estado de Oaxaca. Ambas lenguas se encuentran en situación fuerte de desplazamiento. Sin embargo, el caso ixcateco es el más apremiante pues prácticamente sus hablantes son ancianos que poco a poco están perdiendo su capacidad auditiva; además sólo se habla en una población, mientras el chocholteco cuenta con hablantes en diversas comunidades que revelan variedades dialectales.

En el caso chocholteco, a diferencia del ixcateco, desde hace algunas décadas han existido diversos esfuerzos y movimientos organizativos por realizar materiales escritos y acciones a favor de la lengua. En la mayoría de los casos, han sido profesores bilingües que, por lo general, fueron educados y alfabetizados en la escuela castellanizante, y se han organizado para dar clases de lengua a los niños. Algunos se han jubilado y, en una suerte de altruismo por la lengua, dan clases a niños de diferentes comunidades. Una profesora afirma que da clases de lengua "para enseñar lo que no se enseñó" cuando trabajaba en las escuelas. Cabe señalar que son pocas las poblaciones en que el chocholteco se transmite en el hogar, por ello la escuela ha sido el espacio en que más se desarrollan acciones a favor de dicha lengua.

Si bien existe muy buena disposición por parte de los maestros jubilados o promotores culturales para enseñar la lengua; en dicho proceso aparece en primera instancia la discusión sobre las variedades dialectales y en segundo lugar la discusión sobre las metodologías de enseñanza y la literacidad. Es decir, pocas veces los profesores de la lengua chocholteca se reúnen para intercambiar metodologías de enseñanza; las pocas veces que se han reunido para dialogar en torno a la lengua, solo muestran los avances o algunos ejercicios aprendidos ex profeso para el evento o reunión en la que se participa: se muestran algunas palabras escritas, traducciones del español al chocholteco de 
canciones, adaptaciones de juegos al chocholteco y/o la creación de pequeñas poesías corales en formato bilingüe español-chocholteco.

En todos los casos se prepara a los niños para las presentaciones, pero pocas veces este aprendizaje se practica o utiliza más allá del aula o como parte de la interacción escolar. Por tal motivo, es difícil constatar una producción y comunicación oral y escrita en chocholteco. Incluso los abuelos comienzan a tener problemas para entablar conversaciones entre ellos, ya sea por cuestiones de inteligibilidad o por falta de práctica comunicativa. Si en el ámbito oral el uso del chocholteco es restringido, en el ámbito escrito es aún menor.

De acuerdo con el investigador Sebastián van Doesburg, el chocholteco tuvo un uso escrito amplio en la época colonial; pero se vio fuertemente reducido con la llegada de políticas más nacionalistas y castellanizantes. Hoy se cuenta con materiales didácticos y monográficos que diversas organizaciones han desarrollado o algunos profesores, de manera individual o con apoyo institucional, han producido. Sin embargo, son de tiraje reducido y con poco o nulo consumo de la población chocholteca, quienes en su mayoría no son hablantes de la lengua o no han recibido una alfabetización en dicha lengua.

A la reducida producción de material escrito se suma la poca competencia comunicativa adquirida en las clases. Muchos alumnos no han tenido oportunidad de escuchar la lengua chocholteca en sus comunidades o la han tenido esporádicamente ${ }^{9}$. Las clases de lengua son clases sobre palabras y frases escritas, traducción español-chocholteco y/o chocholteco-español, pero no hay producción oral ni escrita. Si un aprendiz es enfrentado a un discurso oral o escrito en lengua chocholteca, la comprensión y fin comunicativo no pueden establecerse.

En términos de RL, la situación de la lengua ixcateca es aún más preocupante, no solo por el reducido número de hablantes sino por el poco acceso a material y discurso oral y escrito en dicha lengua. Los hablantes de la lengua ixcateca muestran fuerte resistencia a brindar información o a transmitir la lengua a las nuevas generaciones. Esto ha derivado en que los trabajos sean reducidos y muchos solo puedan ser validados por un especialista en la lengua ixcateca cuyo conocimiento es más científico que cultural y pragmático. Existen pocos conocedores o "hablantes pasivos" que puedan ayudar a crear o generar acciones a favor de la lengua ixcateca. La situación de desplazamiento del ixcateco ha sido de interés desde hace varias décadas, por lo que se le ha otorgado a la escritura un valor supremo.

El sentido de efemeridad y de pérdida irremediable de la tradición oral, se nos ha dicho, son razones poderosas para intentar "fijar" la diversidad de figuras narrativas, tales como 
cuentos y leyenda, refranes, dichos y consejas, romances y canciones, entre otras. Argumentos que, si bien son válidos, puesto que sabemos que la formalización rigurosa provoca cambios estructurales en ese pasaje de lo oral a los escrito y viceversa, no son de ninguna manera válidos para contraponer o escindir, artificialmente, la continuidad natural, continuidad, que existe entre oralidad y escritura (Padrón, 2009: 12).

Las acciones a favor del ixcateco se han reducido a la documentación lingüística, dejando de lado su transmisión. Si bien existen clases de lengua en la escuela, esta se reduce a la enseñanza de listas de palabras y a la escritura. Cuando se piensa en realizar una acción o material a favor del ixcateco, se tiene que pensar en la validación que el especialista haga de la escritura y pronunciación de la lengua. Asimismo, entre los propios hablantes hay constante corrección de su producción de discurso; a pesar de ello, la situación de desplazamiento no se revierte.

Los géneros discursivos del ixcateco producidos de manera cotidiana y desde una perspectiva pragmática comienzan a quedar silenciados, mientras la estandarización de las grafías y la corrección del habla todavía preocupan tanto a los pocos hablantes como a los especialistas. Recordando las palabras de Leopoldo Valiñas, en el caso ixcateco es evidente que:

[La estandarización y un conjunto de grafías no siempre eleva a las lenguas indígenas] el nivel cultural, ni económico, ni político ni nada. Y generalmente se piensa esto como si la lengua estuviera esperando simplemente signos para cumplir sus funciones sociales, como si las lenguas indígenas fueran algo exterior de la realidad indígena, como si los hablantes no controlaran su lengua (Valiñas, 1987: 123).

Los casos expuestos muestran que, al no existir una literacidad ampliada en las lenguas indígenas, no existe producción y consumo ampliados de literatura en lenguas indígenas. Es decir, las producciones son esporádicas porque los lectores y consumidores potenciales no cuentan con una competencia comunicativa y, mucho menos, lectora en lenguas indígenas.

El problema que muestra la literacidad en lenguas indígenas, a partir de privilegiar la estandarización y alfabetización en lugar de fomentar el uso cotidiano y comunicativo de las mismas, permite observar la complejidad de no solo imaginar la RL, sino la producción y consumo de literatura indígena por hablantes plenos de la lengua. Si bien ya existen ciertos caminos abiertos por algunos artistas indígenas, aún falta mucho por conquistar.

\section{Consumo de literatura en lenguas indígenas}

En los últimos años, en México, ha habido un boom del fomento a la lectura, en dos sentidos. El primero, más reflexivo, tiene que ver con los mediadores de lectura, aquellos 
interesados en "construir lectores", pues "la lectura ayuda a las personas construirse, a descubrirse, a hacerse un poco más autoras de su vida, sujetos de su destino, aun cuando se encuentren en contextos socialmente desfavorecidos" (Petit, 2001:31). El segundo sentido, desde la perspectiva de la globalización, tiene relación con las industrias culturales y creativas, y su potencial económico para los países (Calagnon y Cesín, 2008). Este artículo sólo retomará el primer sentido.

El potencial cognitivo que estimula la lectura, así como el incremento del capital cultural del lector (Bourdieu, 1987) es totalmente benéfico. Sin embargo, no basta una fila de libros o una buena biblioteca potencialmente utilizada, sino crear hábitos lectores. Es decir, "cuando una persona utiliza diariamente la lectura para obtener parte de la información que requiere, podríamos considerar que ha adquirido hábitos lectores" (Agudo, 1984: 26).

El capital cultural del lector se incrementa a partir de que la lectura entra en su vida cotidiana. Cualquier ejercicio de lectura es parte de la construcción del hábito lector: desde leer un instructivo para realizar una acción procesual, hasta leer una novela de León Tolstoi. Sin embargo, "para que un niño se convierta en lector, sabemos cuán importante es la familiaridad física precoz con los libros, la posibilidad de manipularlos para que los objetos no lleguen a invertirse de poder y provoquen temor" (Petit, 2001: 35). Es necesario que el acercamiento temprano a los libros y al ejercicio de la lectura no se conciba dentro de una escuela sino en el ámbito familiar. Si el niño o adolescente crece sin contexto lector, su inserción al mundo de la lectura y escritura será más lenta y, en algunos casos, prácticamente no sucederá.

Por tal motivo es pertinente mostrar la funcionalidad de la lectura a los públicos potenciales. "Promover lectura significa crear hábitos, educar o reeducar percepciones, y generar o cambiar actitudes" (Agudo, 1984: 28). En México hay diversos programas generados desde las instituciones estatales y de organizaciones de la sociedad civil en los cuales se promueve la lectura en voz alta como una forma de potencializar y revalorizar el acto y capacidad humana de "narrar". En palabras de Judit Vergara Monreal (Comunicación personal, junio de 2005): la lectura en voz alta es un acto de amor, pues trata de trasmitir un mundo por medio de la palabra a quienes, por lo general, tienen un acceso limitado al mundo letrado.

El número de lectores en México se ha incrementado por los espacios publicitarios masivos que se otorgan a la lectura. Frases como: "Usar lentes te da estilo, leer te da cultura"; la aparición de trilogías o sagas, divulgadas en el cine, incrementan las ventas de libros. Sin embargo, el acto de narrar oralmente se ha ido restringiendo al ámbito de la narración del texto escrito (Padrón, 2009). Si esto sucede alrededor del mundo con las lenguas modernas, para las lenguas indígenas es un acto cada vez más restringido y en riesgo de desaparición. 
Las acciones a favor de la preservación de las lenguas indígenas han llevado a documentar la tradición oral y generar diversas colecciones bibliográficas sobre tradición oral indígena en diversas lenguas, la proliferación de concursos de literatura indígena, así como de poetas y escritores indígenas. Sin embargo, lo que se está perdiendo es el arte oral de narrar en lengua indígena, así como la transmisión intergeneracional de la propia lengua. En el mejor de los casos esta literatura tiene que recurrir al recurso bilingüe español-lengua indígena, provocando una no-necesidad de aprender la lengua, que es folklorizada. Cuando el recurso es monolingüe indígena, los libros se quedan guardados en los estantes de las librerías o bibliotecas o se convierten en souvenir para visitantes; pues no hay lectores en lenguas indígenas.

A partir de esto se observa que la producción y consumo de literatura indígena son restringidas porque no existe un público amplio que demande esta literatura. Es decir, en cualquier coloquio o encuentro de lenguas se hace referencia a la necesidad de producir estos materiales, pero no existen programas que formen los lectores de lenguas indígenas. Aunque existen esfuerzos literarios para fortalecer el uso de las lenguas, el proceso es incipiente y en nada asegura la vitalidad de ellas. En términos de consumo cultural, hace falta mucho trabajo de planificación para la promoción literaria, un trabajo previo que pocos toman en cuentan, que es "transmitir, usar y narrar" diversas visiones del mundo en lenguas indígenas.

\section{Conclusiones}

En el campo de la RL cualquier acción a favor de las lenguas es bienvenida, pues se ha comprobado que es importante motivar a los hablantes y hablantes potenciales a hacer un uso ampliado de la lengua. La literacidad y el desarrollo de la literatura en lenguas indígenas se conciben como pasos necesarios para lograr que dichas lenguas ingresen a nuevos espacios de uso, así sean una motivación simbólica para recuperar los espacios de donde han sido desplazadas. Sin embargo, como se ha mostrado en estos casos del sur de México, aún falta mucho trabajo por desarrollar, pues se ha otorgado mucho más importancia a la escritura que a la oralidad, y con ello el uso de las lenguas como vehículo comunicativo principal se ha visto relegado al ámbito escolar.

En México, y en el estado de Oaxaca y Chiapas, existen muchos poetas y literatos indígenas. Si bien distintos esfuerzos institucionales les han otorgado un reconocimiento extenso, que ha traspasado las fronteras nacionales, estos artistas de la palabra escrita son poco conocidos y consumidos dentro de las propias comunidades de origen. Incluso llegan a ser considerados como el ejército de la lengua escrita, una lengua o variedad que no pertenece a la pragmática de las comunidades de hablantes. 
El consumo literario en el país es reducido; los programas de formación de lectores no han logrado incidir en el ámbito familiar y en la socialización temprana de los ciudadanos. En este contexto, el consumo literario en lenguas indígenas es mucho más reducido, pues suma los fracasos de la alfabetización y de la perspectiva reduccionista en torno a la literacidad, a las condiciones de desigualdad social y estigmatización, y a la producción y circulación reducidas del material en lengua indígena. Sin embargo, la problemática en torno al consumo literario en lenguas indígenas no se solucionaría con el incremento del material, que es lo que los hacedores de políticas lingüísticas y promotores culturales por lo general piensan y materializan en la traducción de grandes escritores de la literatura universal a las lenguas indígenas.

Incrementar los lectores en lengua indígena no se logra desde una perspectiva universalista y estándar de la lengua y la escritura. El desplazamiento de las lenguas indígenas se debe a la renuncia de sus hablantes a transmitirlas y usarlas. Por lo tanto, mientras esta renuncia no sea revocada y se generen competencias comunicativas en lengua indígena, el ámbito de la literatura quedará reducido a los artistas indígenas y en quienes desde su perspectiva exótica disfruten de ella. Si bien es necesario reconocer los usos no institucionales de la escritura, lo es también construir una crítica más amplia a la perspectiva institucional y formal de la escritura de las lenguas indígenas, pues es la perspectiva hegemónica y forma parte de las ideologías de los hablantes y no hablantes de las lenguas.

Por tal motivo, es necesario revisitar el tema del uso de las lenguas y su transmisión, así como la re-evaluación de los sistemas de enseñanza de lectoescritura. Es necesario un análisis crítico de los avances sobre las lenguas indígenas. No basta generar materiales escritos, es necesario que estos materiales entren y salgan de distintos ámbitos y para ello es necesario pensar en la formación de lectores, así como en la formación de escritores que disfruten de las narraciones orales y escriturales sin necesidad de la traducción de la lengua indígena al español. Si en algún momento los hablantes de las lenguas indígenas comienzan a disfrutar y decodificar la literatura producida en su lengua, podremos decir que las lenguas están siendo revitalizadas, pues se habrá recobrado el arte de narrar en lenguas indígenas. De lo contrario, seremos testigos de su paulatina desaparición, aunque contemos con millones de escritos en esas lenguas. 


\section{Referencias}

AGUDO, A. (1984). La promoción de la lectura como animación cultural. Parapara, (9), 25-37.

ALIMI, M. (2015). Micro language planning and cultural renaissance in Botswana. Language Policy, Febrero, 1-21.

AVILÉS, T. y ROJAS, D. (2014). Argumentación y estandarización lingüística: creencias normativas en el Diccionario de chilenismos (1875) de Zorobabel Rodríguez. Revista Signos. Estudios de Lingüistica, (85), 142-163.

BARANDIARAN, X. (2003). Activismo digitaly telemático. Podery contrapoder en el ciberespacio, Versión 1(1). http://sindominio.net/ xabier/textos/adt/adt.html

BOURDIEU, P. (1987). Los Tres Estados del Capital Cultural. Sociológica, 2(5), 11-17.

CALAGNON, N. y CESÍN E. E. (2008). Nosotros y los otros: comercio exterior de bienes culturales en América del Sur. Buenos Aires: Secretaría de Cultura de la Presidencia de la Nación.

CÓRDOVA, L. (2009). "Ideologías lingüísticas de una comunidad de habla chuj en la zona fornteriza del estado de Chiapas", Tesis de maestría. Centro de Investigaciones y Estudios Superiores en Antropología Social, México.

CRAGNOLINO, E. y LORENZATTI, M. C. (2013). Jóvenes, familias y procesos de literacidad. Cuadernos CEDES, 33(90), 197-214.

CRU, J. (2015). Language revitalisation from the ground up: promoting Yucatec Maya on Facebook. Journal of Multilingual and Multicultural Development, 36(3), 284-296.

DURÁN, S. (2013). Estrategias para la enseñanza de lenguas moribundas por maestros con poco dominio de ellas. Científica, 1(2), 155-169.

FERREIRO, EMILIA (2012) [1989]. Introducción. En Ferreiro, E. (coord.) Los hijos del analfabetismo. Propuestas para la alfabetización escolar en América Latina (pp. 9-15). México: Siglo XXI.

FLORES, J. A. y CÓRDOVA, L. (2012). Guía de revitalización lingüistica: para una gestión formada e informada. México: CIESAS/Conacyt/Inali/Ediciones el Lirio.

HAMMER, C. S., E. HOFF, Y. UCHIKOSHI, C. GILLANDERS, D. C. CASTROE y L. E. SANDILOS (2014). The language and literacy development of young dual language learners: A critical review. Early Childhood Research Quarterly, (29), 715-733.

HAYNES, E. F. (2011). When support for language revitalization is not enough: the end of indigenous language classes at warm springs elementary school. International Journal of the Sociology of Language, (209), 141-155.

HINTON, L. (2001). Language Revitalization: An Overview. En L. Hinton y K. Hale (ed.), The Green Book of Language Revitalization in Practice (pp. 3-18). San Diego/Boston: Academic Press. 
HORNBERGER, N. (1996). Language Planning from the Bottom Up. En Hornberger, N. (ed.), Indigenous Literacies in the Americas. Language Planning from the Bottom Up (pp.357-366). Berlín: Mouton de Gruyter.

JOHNSON, D. C. y JOHNSON, E. J. (2015). Power and agency in language policy appropriation. Language Policy, (14), 221-243.

KINGSLEY, L. (2009). Explicit and implicit dimensions of language policy in multilingual banks in LuxembourgAn analysis of top-down and bottom-up pressures on practices. Language Problems \& Language Planning, 33 (2), 153-173.

LEMUS JORGE E. (2010) "Un modelo de revitalización lingüística: El caso del nahuat/pipil de El Salvador". Wani Revista del Caribe Nicaragüense, (62), 25-4.

LÓPEZ, L. E. (2008). Top-down and Bottom-up: Counterpoised Visions of Bilingual Intercultural Education in Latin America. En Hornberger, N. (ed.). Can schools Save Indigenous Languages? Policy and Practice on Four Continents (pp. 42-65). New York: Palgrave Macmillan.

MAKIHARA, M. (2013). Language, competence, use, ideology, and community on Rapa Nui. Language \& Communication, (33), 439-449.

MIJANGOS E., y LOPEZ, A. (2011). El problema del indigenismo en el debate intelectual posrevolucionario. Signos Históricos, 13 (25), 42-67.

MOORE, D., y MACDONALD, M. (2013). Language and literacy development in a canadian native community: Halq'eméylem revitalization in a stó:Lō head start program in british columbia. The Modern Language Journal, 97(3), 702-719.

NAVSARIA, D. y SANDERS, L. M. (2015). Early literacy promotion in the Digital Age. Pediatric Clinics of North America, 62 (5), 1273-1295.

PADRÓN, O. (2000). En torno al lenguaje y sus significados: En el contexto de la promoción de la lectura. Caracas: Fundalectura.

PETIT, M. (2001). Lecturas: del espacio intimo al espacio público. México: Fondo de Cultura Económica.

SKERRETT, M.E. (2012). Counter colonization through Maori language revitalization in Aotearoa/ New Zealand. 20th Reconceptualizing Early Childhood Education Conference, 4-7 Noviembre 2012, University Park, Pensilvania.

VALADEZ, C., ETXEBERRIA, F., y INTXAUSTI, N. (2015). Language revitalization and the normalization of Basque: a study of teacher perceptions and expectations in the Basque Country. Current Issues in Language Planning, 16 (1-2), 60-79.

VALIÑAS, L. (1987). ¿Hay alfabetos bilingües-biculturales? Santa Clos y lo bilingüe-bicultural, dos mitos que nadie cree. En Muñoz, H. (ed.). Funciones Sociales y Conciencia del Lenguaje. Estudios sociolingüísticos (pp. 119-127). México: Universidad Veracruzana. 
YATACO M. y CÓRDOVA, L. (en prensa) "Visibility and revitalization of Latin American indigenous languages: production of linguistic landscape and signage". 